\title{
Self-consolidating mortar incorporating higher volume blended pozzolans for concrete repair
}

\author{
M. Jamil ${ }^{1}$, A. B. M. A. Kaish ${ }^{2,}$, E. I. Sahari ${ }^{2}, N . L$. Fong ${ }^{2}$, and $L . \mathrm{Nahar}^{3}$ \\ ${ }^{1}$ Centre for Innovative Architecture and Built Environment (SErAMBI), Universiti Kebangsaan \\ Malaysia, UKM Bangi, Malaysia. \\ ${ }^{2}$ Department of Civil Engineering, Infrastructure University Kuala Lumpur, Kajang, Malaysia \\ ${ }^{3}$ Institute of Visual Informatics, Universiti Kebangsaan Malaysia, UKM Bangi, Malaysia
}

\begin{abstract}
The challenge of repairing cracked or damaged concrete has been increasing worldwide. Several cement-based materials, such as ferrocement, fiber-reinforced cementitious mortar (FRCM), and textilereinforced mortar (TRM), have been developed and used to address the aforementioned challenge. Self-consolidating mortar is required to accelerate structural concrete repair using cementitious composites (e.g., ferrocement, FRCM, and TRM). In this study, a high-strength selfconsolidating mortar is developed using higher-volume (50\% by weight of cement) blended pozzolans. Experimental results exhibit potential in terms of flowability and strength. Therefore, this type of cementitious selfconsolidating mortar can be used to expedite concrete repair or strengthening using cementitious composites.
\end{abstract}

\section{Introduction}

Concrete and reinforced concrete is the most commonly used construction materials at present. The annual consumption of concrete worldwide exceeds 11 billion tons. The high compressive strength and high-alkaline nature of concrete make it perfect for use as reinforced concrete in structural applications. Despite the high compressive strength of concrete, it suffers from low tensile strength and brittleness that lead to cracking. Typical causes of cracks are overloading humidity and temperature variations, and change in usage [1].

The retrofitting or repair of deteriorated concrete structures has become a growing challenge [2]. Several materials have been developed and used to address this challenge. The application of epoxy and cement slurry injection to repair cracked concrete has been reported in the literature [3]. Strengthening concrete structures using fiber-reinforced polymer has become a common practice worldwide [4-6]. Ferrocement has also been reported as an effective and low-cost material for strengthening concrete structures $[1,2,7-$ 11]. Textile-reinforced mortar (TRM) and fiber-reinforced cementitious mortar (FRCM) are promising materials for strengthening concrete structures [12-14].

\footnotetext{
* Corresponding author: amrul.cuet@gmail.com; amrul.kaish@iukl.edu.my
} 
Ferrocement, FRCM, and TRM comprise layers of cement mortar reinforced with steel or other types of meshes. ASTM C 219-03 defined mortar as "a mixture of finely divided hydraulic cementitious material, fine aggregate, and water" [15]. Structural mortar is expected to resist certain external forces and provide strength. In strengthening applications, mortar is assumed to carry a part of the load. Therefore, the mortar component of ferrocement and FRCM must also be sufficiently strong to carry loads. Simultaneously, the application of self-consolidating mortar can eliminate the placement problem in the mortar, and therefore, can reduce time and human resources requirements [16]. Hence, high-strength self-consolidating mortar can provide a solution to the challenge of repairing concrete structures. However, high-strength mortar requires a high volume of cement, which results in high material cost. Moreover, the use of high-volume cement is discouraged due to sustainability issues in construction. Therefore, an alternative to using high-volume cement must be explored.

One option that can address this setback is to replace cement with high-volume pozzolanic materials, such as industrial wastes (e.g., fly ash, silica fume, slag, and alum sludge) and agricultural waste ashes (e.g., rice husk ash and palm oil fuel ash) [17-20]. Research on the application of multiple blended pozzolans to produce high-strength mortar has not been reported extensively in the existing literature. Therefore, the current study is conducted to investigate the applicability of multiple blended pozzolanic materials (i.e., fly ash, silica fume, and slag) to replace higher-volume cement in a high-strength selfconsolidating mortar.

\section{Materials and methods}

\subsection{Materials}

Locally sourced ordinary Portland cement (OPC) with blended pozzolans was used as the binder material. First, 50\% OPC was replaced with a mixture of locally sourced silica fume, fly ash, and slag. The relative densities of cement, silica fume, fly ash, and slag were 3.15 , $2.10,2.25$, and 2.85 , respectively. The individual percentages of the pozzolans used in the blended mix are provided in Table 1. River sand, which was sifted through a $1.18 \mathrm{~mm}$ sieve and had a specific gravity of 2.60 , was used as the fine aggregate in the mortar mix. Tap water supplied to the concrete laboratory was utilized for mortar mixing and specimen curing. A commercially available polycarboxylate-based superplasticizer was used to maintain the self-consolidating properties of the mortar mixes.

\subsection{Mix design}

The mortar mix was designed on the basis of a fine aggregate-to-binder ratio of 1.0 by weight. Blended cement with higher-volume (50\%) blended pozzolans was used as the binder material. The blended pozzolans were produced using a mixture of fly ash, silica fume, and slag. The water-to-binder ratio was maintained at 0.25 to achieve high strength. To realize a self-consolidating property, the superplasticizer was utilized as $4 \%$ of cement by mass. The control mortar did not contain any pozzolanic materials, but different proportions of pozzolans were used in the blended mortar. Different ratios of pozzolans were considered to obtain the optimum mix concerning flowability and strength. The mortar mix proportions are presented in Table 1. 
Table 1. Mortar mix proportions.

\begin{tabular}{|c|c|c|c|c|c|c|c|}
\hline \multirow{2}{*}{$\begin{array}{c}\text { Mix } \\
\text { designation }\end{array}$} & \multirow{2}{*}{$\begin{array}{l}\text { Cement } \\
\left(\mathrm{kg} / \mathrm{m}^{3}\right)\end{array}$} & \multirow{2}{*}{$\begin{array}{c}\text { Sand } \\
\left(\mathrm{kg} / \mathrm{m}^{3}\right)\end{array}$} & \multirow{2}{*}{$\mathbf{W} / \mathbf{C}$} & \multirow{2}{*}{$\begin{array}{l}\text { Superplasticizer } \\
\text { (\% of cement) }\end{array}$} & \multicolumn{3}{|c|}{$\begin{array}{l}\text { Pozzolanic materials } \\
\qquad\left(\mathrm{kg} / \mathrm{m}^{3}\right)\end{array}$} \\
\hline & & & & & $\begin{array}{l}\text { Silica } \\
\text { fume }\end{array}$ & $\begin{array}{l}\text { Fly } \\
\text { ash }\end{array}$ & Slag \\
\hline $\mathrm{CM}$ & 880 & 880 & 0.25 & 4 & 0 & 0 & 0 \\
\hline BM-1 & 440 & 880 & 0.25 & 4 & 88 & 0 & 352 \\
\hline BM-2 & 440 & 880 & 0.25 & 4 & 88 & 88 & 264 \\
\hline BM-3 & 440 & 880 & 0.25 & 4 & 88 & 176 & 176 \\
\hline BM-4 & 440 & 880 & 0.25 & 4 & 88 & 264 & 88 \\
\hline BM-5 & 440 & 880 & 0.25 & 4 & 88 & 352 & 0 \\
\hline
\end{tabular}

\subsection{Casting and curing}

The mortar was mixed in a Hobart mixer using the proportions given in Table 1. First, all the materials were mixed thoroughly in the dry state. Then, the water mixed with the superplasticizer was added slowly. An extended mixing time (10 min) was used to break the pozzolan and cement clumps in the dry material to obtain a fluid mix following ASTM C 305 [21]. After preparation, the mix was poured into standard cylindrical $(50 \mathrm{~mm}$ diameter and $100 \mathrm{~mm}$ height $)$ and cube $(50 \times 50 \times 50 \mathrm{~mm})$ molds. All the specimens were wrapped with thin plastic paper to prevent evaporation from the surface. The specimens were demolded after approximately $24 \mathrm{~h}$ of casting. The specimens were then kept underwater in a plastic chamber inside the concrete laboratory until the testing age. Fig. 1 shows the molding and curing processes of the mortar specimens.

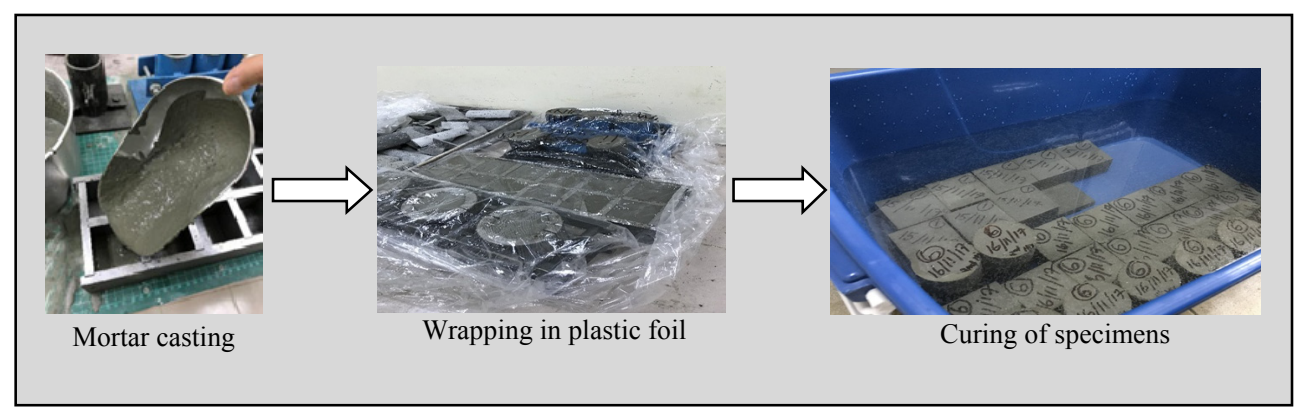

Fig. 1. Casting and curing process.

\subsection{Testing}

After mixing, the fresh mortar mixes were used to fill in a Hägermann cone in the form of a frustum to determine the flow value of mortar. The conical mold was lifted straight upward to allow the free flow of mortar. Two diameters that were perpendicular to each other were determined toward the end when the horizontal flow of mortar stopped. The mean of the 
diameters was recorded as the slump flow value. The fresh density of mortar was determined before pouring it into molds. Compressive and tensile strengths were determined by crushing the mortar cube and splitting the mortar cylinder under compression, respectively.

\section{Results and discussion}

\subsection{Slump flow and fresh density}

The slump flow and fresh density of the mortar mixes are presented in Fig. 2. The mortar specimens without pozzolans achieved a slump flow of $245 \mathrm{~mm}$, which is slightly higher than the allowable flow value of $240 \mathrm{~mm}$. However, the BM-1 mortar presented a slightly lower flow value. The remaining specimens exhibited good flowability regarding flow value. The flowability of mortar increased with an increase in fly ash amount. The rounded particles of fly ash can explain the increased flow value. Therefore, the developed mortar mixes can be used reasonably in concrete repair by filling in narrow cracks.

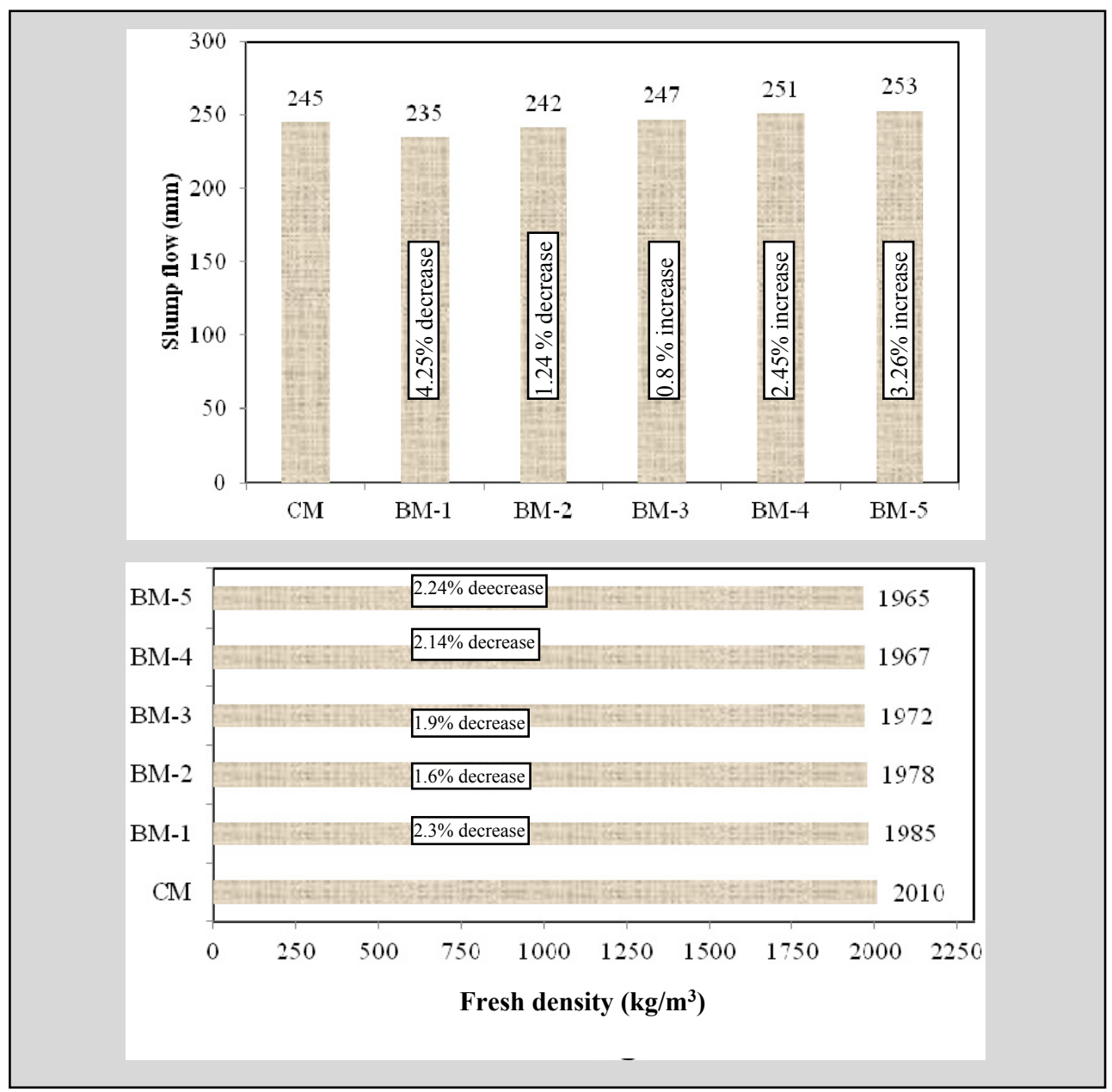

Fig. 2. Slump flow and fresh density of mortar mixes. 
As shown in Fig. 2, fresh density varied from 1965-2010 kg/m ${ }^{3}$. Density decreased with an increase in pozzolan content, which could be explained by the lower unit weight (or specific gravity). The application of a material with a low unit weight is beneficial in reducing the total weight of a building.

\subsection{Compressive strength}

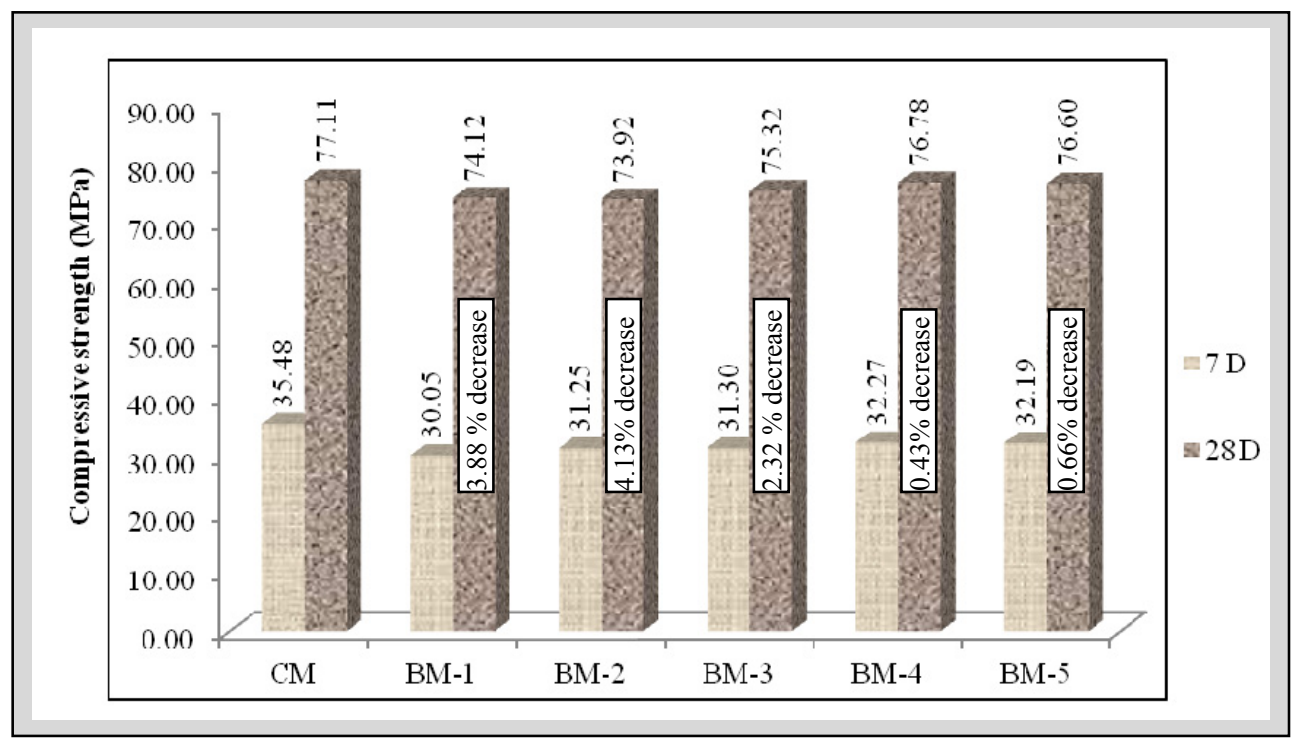

Fig. 3. Compressive strength of mortar mixes.

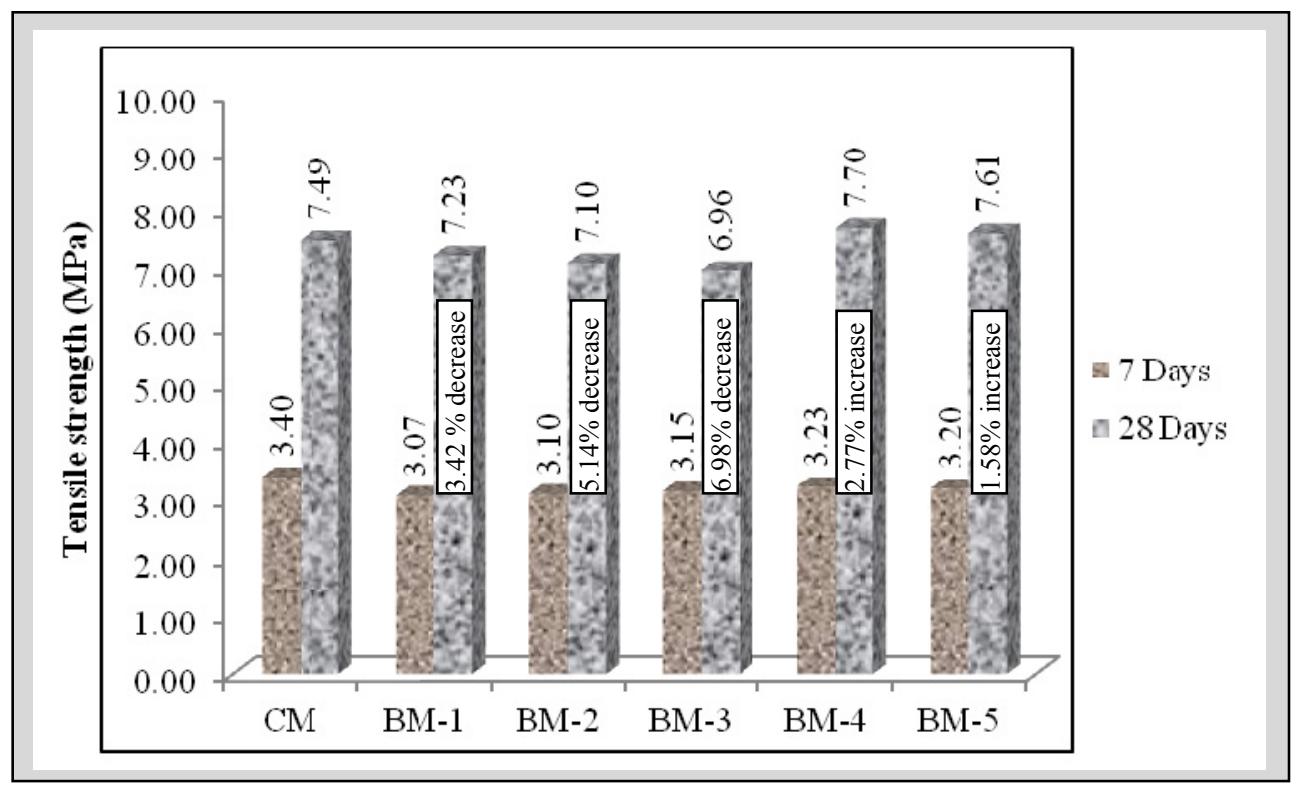

Fig. 4. Tensile strength of mortar mixes.

The compression strength test was conducted on $50 \mathrm{~mm}$ cube specimens at 7 and 28 days using a compression testing machine. The results, which are presented in Fig. 3, showed that all the mortar specimens with pozzolans exhibited slightly lower strength than the 
control mortar at 7 and 28 days. At seven days, the mortars with blended pozzolans presented considerably lower strength than at 28 days because the pozzolanic reaction was weaker in the first few days. Thereafter, the rate of pozzolanic reaction increased due to the availability of $\mathrm{Ca}(\mathrm{OH})_{2}$. Thus, the strength of mortars with blended pozzolans was extremely close to that of the control mortar at 28 days.

\subsection{Tensile strength}

Fig. 4 shows the tensile strength of different specimens obtained from the experiments conducted at 7 and 28 days. The trends for tensile strength development are similar to the trends for compressive strength development. Strength development at seven days was slow due to the low amount of cement and $\mathrm{Ca}(\mathrm{OH})_{2}$, which resulted in a poorly developed interfacial transition zone. At 28 days, however, the tensile strength was considerably higher and nearly close to that of the control specimens. In specimens with a higher amount of fly ash, tensile strength exceeded that of the control specimens.

\section{Conclusions}

The following conclusions can be drawn from the analysis of the results. The flowability of the mortar mixes increases with an increase in fly ash content. However, the inclusion of silica fume decreases flowability. Fresh density decreases with the addition of pozzolans due to the low unit weight of the pozzolans. Compressive and tensile strengths are comparable with those of the control mortar mix. Specimens with higher fly ash content achieve better results, which may be attributed to high flowability. This experiment presents promising results for cement mortar with blended pozzolans. However, more comprehensive trials are required to validate its practical application. In particular, microstructure characterization and durability properties must be investigated further.

The authors acknowledge the funding and support received for this research from the Centre for Innovative Architecture and Built Environment (SErAMBI), Universiti Kebangsaan Malaysia through the research grant DIP-2016-06; and the Department of Civil Engineering, Infrastructure University Kuala Lumpur, Malaysia.

\section{References}

1. A.B.M.A. Kaish, M.R. Alam, M. Jamil, M.F.M. Zain, M.A. Wahed, Con. Build. Mat. 36, 11 (2012)

2. A.B.M.A. Kaish, M.R. Alam, M. Jamil, M.F.M. Zain, M.A. Wahed, Proc. Eng. 54, (2013)

3. C.A. Issa, P. Debs, Con. Build. Mat. 21, 1 (2007)

4. H.M. Elsanadedy, Y.A. Al-Salloum, S.H. Alsayed, R.A. Iqbal, Con. Build. Mat. 29, (2012)

5. W. Wang, M.N. Sheikh, M.N.S. Hadi, Mat. Struct. 49, 9 (2016)

6. M.N.S. Hadi, A.H.M. Algburi, M.N. Sheikh, A.T. Carrigan, Con. Build. Mat. 172, 30 (2018)

7. I. Ho, E. Lam, B. Wu, Y. Wang, J. Struct. Eng. 139, 4 (2013)

8. A.B.M.A. Kaish, M. Jamil, S.N. Raman, M.F.M. Zain, Con. Build. Mat. 78C, (2015)

9. A.B.M.A. Kaish, M. Jamil, S.N. Raman, M.F.M. Zain, M.R. Alam, Mat. Struct. 49, 3 (2016) 
10. M.J. Shannag, S.M. Mourad, Con. Build. Mat. 36 (2012)

11. A.B.M.A. Kaish, M. Jamil, S.N. Raman, M.F.M. Zain, L. Nahar, Con. Build. Mat. 160 (2018)

12. L. Ombres, Comp. Struct. 176 (2017)

13. A. Cascardi, F. Longo, F. Micelli, M.A. Aiello, Con. Build. Mat. 156 (2017)

14. O. Awani, T. El-Maaddawy, N. Ismail, Con. Build. Mat. 132 (2017)

15. ASTM, Standard Terminology Relating to Hydraulic Cement ASTM C219-03 (ASTM International, West Conshohocken, 2003)

16. S. Sakir, S.N. Raman, A.B.M.A. Kaish, A.A. Mutalib, Perspectives in Science 8 (2016)

17. M.J. Shannag, Cem. Con. Res. 32 (2002)

18. M. Jamil, A.B.M.A. Kaish, S.N. Raman, M.F.M. Zain, Con. Build. Mat. 47 (2013)

19. M. Jamil, M.N.N. Khan, M.R. Karim, A.B.M.A. Kaish, M.F.M. Zain, Con. Build. Mat. 128 (2016)

20. A.B.M.A. Kaish, K.M. Breesem, M.M. Abood, J. Clean Prod. 202 (2018)

21. ASTM, Standard Practice for Mechanical Mixing of Hydraulic Cement Pastes and Mortars of Plastic Consistency ASTM C305-14 (ASTM International, West Conshohocken, 2003) 